\title{
Isabel Alvarez
}

Ph.D., Auxiliary Professor, Faculty of Economics and Business Communications

The Lisbon Lusíada University, Lisboa, Portugal

alvarez@edu.ulusiada.pt

ORCID: 0000-0003-4381-6328

\section{Paulo Pinto}

$\mathrm{PhD}$, Auxiliary Professor of Faculty of Economy and Enterprise Sciences

The Lisbon Lusíada University, Lisboa, Portugal

pjpinto@lis.ulusiada.pt

ORCID: 0000-0002-0675-6293

\author{
Nuno Sotero da Silva \\ Lecturer of Faculty of Economy and Enterprise Sciences and IT Manager \\ The Lisbon Lusíada University, Lisboa, Portugal \\ nsas@lis.ulusiada.pt \\ ORCID: 0000-0003-0157-0710
}

\section{LIFELONG LEARNING - A LOCAL CASE OF SUCCESS USING WEB TEXT- BASED DISCUSSION FORUMS}

\begin{abstract}
The work environments raise changes associated with both economic and social demand in an internationally competitive context. The focus of this paper is the perspectives of people, both employers and employees, who are engaged in lifelong e-learning, within the Portuguese economy. It critically reflects on recent experience at a small local institution considering whether complex state-of the art technology becomes a key to the development of lifelong learning practices in a knowledge-based society.
\end{abstract}

Keywords: lifelong e-learning; distance learning; organizational context; case study; lecturing experience

Introduction. The Internet has been identified as a potential enabler of lifelong learning. Web-based learning systems enable workers to participate in learning activities without the time and distance constrains. Lifelong learning provides the opportunity for the discussion and collaborative knowledge construction to enable learners in acquiring knowledge in the context of learning, working and collaboration associated with a positive evaluation of scientific/technical knowledge.

This paper will examine the contribution of lifelong learning to organizational development, specifically in relation to e-learning courses by distance learning. In this context, lifelong elearning is used by employees to improve their current, or future, employment prospects as well as by employers as a way of improving their organizational performance.

This paper draws on the first author's experience of e-teaching and of distance tutoring students who are in full time employment and critically reflects on the recent experience at a small local institution considering whether complex state-of the art technology becomes a key to the development of lifelong learning practices in a knowledge-based society. In the first part, the paper is theoretical in its orientation of lifelong education, whereas in the second part it makes an overview of the web text-based discussion forums lifelong learning system in use in the institution under study. The third and last part of the paper presents, discusses and assesses the findings related to the learners' opinions on a variety of aspects of their lifelong vocational training courses and explores the significance of the use of simple technology as to the meanings it may bring to the development of lifelong learning practices.

What is lifelong learning? Smith and Spurling (1999) provided a simple definition of lifelong learning, that it relates to people learning consistently throughout their lifespan, covering all life from the cradle to the grave, and which may start at any age.

Through lifelong learning the decision to study is much easier then more traditional 
methods of learning. There is no need for the learner to alter dramatically their schedule as they would need to if they were attending a traditional course. Instead, they need to adjust their lives to provide time for study at a time which is convenient to them be that at midnight or on weekends.

With the globalization of economy vast social and economical changes are taking place. Within these changes the ability to continue to learn is very important.

Lifelong learning in an organizational context. The work environments raise changes associated with both economic and social demand in an internationally competitive context. A world characterized by rapid and unpredictable change, uncertainty and ambivalence, where knowledge is not only constantly changing but is becoming more rapidly and overwhelmingly available (Edwards, 1997 p.16). Lifelong learning is significant as it is possible for employees to work fulltime and at the same time to pursue learning opportunities in their 'own time' and at any time of their choosing.

Osborne and Oberski (2004, p.414) held that "a prevailing discourse within lifelong learning in an organizational context is that of flexibility of provision on meeting students' needs at time and places of their own (or their employers') choice and the availability of open and distance learning opportunities based on the use of communication and information technologies seems to be especially important in achieving this flexibility." Phillips (1991) refers several areas where organizations might expect to find positive results from employees being involved in learning, and or developmental experiences like cost and time savings, improved working habits and climate, which would be evidenced by low, or reduced, turnover, staff commitment and satisfaction.

Case Study - Lecturing Experience.

Introduction. The institution under study is a small editor, located in Lisbon and specialized in publishing accounting, management and engineering/production books. They had already some experience in organizing training or seminar sessions, focusing on several business subjects, for their customers. In 2008 they decided to start online life-long training courses. The majority of their customers were in remote areas away from the main towns where the traditional training sessions had always been organized.

Design of the system. After some initial discussions on how this project could be implemented, it was decided to use Moodle as the e-learning platform.

Following is an overview of the web text-based discussion forums lifelong learning system in use in the institution under study.

Care attention and thought was given on how to design e-learning content that would attract users, addressing the practical needs. To fit the nature of lifelong learning, content should be practical so it is easy for users to engage with while still in the flow of their routine daily performance (Fischer \&Konomi, 2007). Simple activities should be designed into the content for meeting the requirements of the potential learning context $(\mathrm{Gu}$ et al, 2011). Also, along with the pedagogical design principles for content and activity, conventional usability principles mainly related to interface design - navigation, control, feedback, error control, consistency and user satisfaction - were considered equally necessary in design (KukulskaHulme 2007).

We found however that for the contents, there was few or none literature on how to develop a proper content for an e-learning course, clarifying on the adequate colors, type and size of letter, text, etc., so it was decided to organize each course in sessions, each one with a maximum of 10 A4 pages, and the number of sessions depending on the complexity of the course, ranging from 7 to 15, with light colors, simple text and an exercise to be solved by the participants at the end of each session.

It was also taken in consideration that some of the participants could belong to small organizations with not very updated and low capacity ICT equipment and that the contents of 
the courses should not be too heavy to download. The sessions could only be downloaded one per week, from the e-learning platform where all the participants were registered and were allowed to access.

Besides the weekly exercise to be solved, there was also a compulsory minimum number of participations in the forums. The maximum response time by the teacher was 48 hours.

Analysis. Finally, a question list was designed to analyze results and opinions of the students for each course. The research questions of this list, which the students had to reply at the end of each course, were designed into four groups - platform, content, activity and usability (San Jose, 2014):

\section{Platform:}

(a) Does the technology platform adopted (Moodle) for the sessions impact students' experience?

(b) Do student characteristics (technological abilities and attitudes) affect the quality of the portfolios students create?

\section{Content:}

(a) Is the length of each session enough to be focused and studied?

(b) Is the frequency of the publication (weekly) of each session convenient?

(c) Are the learning materials of each session self-contained units that can be fit into small time slots?

\section{Activity:}

(a) Is it overwhelming to learn in a fragmental way with a computer screen?

(b) Is all the information that is essential displayed on the screen?

(c) Does the learning materials serve your practical learning needs?

(d) Are the session weekly exercises clear enough to put in practice what has been explained in the session?

\section{Usability:}

(a) Do you feel comfortable with the layout and style of the interface?

(b) Are the menu items of each page consistent from screen to screen? -

(c) Are the color combination used suitable for an online study?

Findings. In this chapter we discuss and assess the findings related to the learners' opinions on the variety of aspects of their lifelong vocational training courses, analyzed by the replies given to the list of research questions referred in 4.1 and explore the significance of the use of simple technology as to the meanings it may bring to the development of lifelong learning practices.

Data from the research questions were analyzed and the results showed that concerning the platform used the students in general (93,3\%) were happy with the it. As for the content the length of the frequency with which each session was published (one per week) was considered low and the general opinion was that two per week would be the right frequency. The length of the sessions was considered (92\%) adequate and the length of the content of each session was thought short enough to be focused, as the generalized opinion was that only essential information was thought to be displayed on the screen. Also for the activity, the participants were positive (94\%) of how the simple design could be integrated into their activities. And finally, the heuristic results for the usability design of 
89\% showed that evaluators were satisfied with most parts of the interface and its consistent design, including the layout, style, color, navigation, and control.

The adherence to these e-learning courses has been very high, and the comments very positive. The participants claimed that this was a good way for them to take training, as due to their remote location the participation to traditional training was almost impossible as that would mean to be away from their work for several days, with high costs, not only for the course but also for accommodation and travelling. With the e-learning they were also able to control and manage their own learning depending on their availability.

Also, the participants of these e-learning courses were keen users of the forums for online discussions on the several subjects studied.

Discussion. So a critical reflection must be made based on this experience whether complex state-of the art technology becomes a key to the development of lifelong learning practices in a knowledge-based society.

We should discuss and assess the findings related to the learners' opinions on a variety of aspects of their lifelong vocational training courses and explore the significance of the use of simple technology as to the meanings it may bring to the development of lifelong learning practices. Multimedia is not necessarily desired for small pieces of content as Gu et al (2011) proved in the findings of their study.

As it is claimed by Kukulska-Hulme (2007), systems for learning products should go beyond merely technical aspects of usability and include pedagogical concerns. In essence, technology has to become invisible to users so that the attention is on achieving the intended learning purpose of the software and not the technology system (Hattie, et al., 2006).

According to Laxman (2010), technology must reflect real world applications to enable meaningful learning from users. Otherwise, the intended goals of improved learning and teaching may be subverted by the interaction of human abilities and attitudes with technological characteristics.

Previous research has found that it is important for any educational technology (a) to be easy to use, (b) to produce a beneficial user experience, and (c) to not distract or prevent users from achieving intended purposes (Hattie, Brown, Ward, Irving, \& Keegan, 2006).

Conclusion. There is a gap in the relevant literature, on e-learning systems, whether concerning the development of contents, actions to be taken towards the different cultural groups, length of the courses, impacts of the text and evaluation or to a commonly accepted proposal that could describe competence related characteristics of educational resources that support the main issues related to the competence-relevant characteristics of lifelong learning by distance.

\section{REFERENCES}

Fischer, G. \& Konomi, S. (2007). Innovative socio-technical environments in support of distributed intelligence and lifelong learning, Journal of Computer Assisted Learning, 23, 338-350

GU, X., et al, (2011). Designing a Mobile System for Lifelong Learning on the move, in Journal of Computer Assisted Learning, 27, 204-215, Blackwell Publishing Ltd

Hattie, J.A., Brown, G.T.L., Ward, L., Irving, S.E., \& Keegan, P.J. (2006). Formative evaluation of an educational assessment technology innovation: Developers' insights into assessment tools for teaching and learning (asTTle). Journal of MultiDisciplinary Evaluation, 5, 1-54.

Kukulska-Hulme, A. (2007). Mobile usability in educational contexts: what have we learnt? , Internationl Review of Research in Open and Distance Learning 8, 1-16

Longworth, N. and Davies, W. K. (1996). Lifelong Learning, Kogan Page, London Osborne 
M. and Oberski I. (2004) University continuing education. The role of communications and information technology, Journal of European Industrial Training, Vol. 28, No. 5, pp. 414-428.

Phillips, J. (1991). Handbook of Training Evaluation and Measurement Methods, Houston, Gulf Publishing

San Jose, D. L. (2014). Does technology matter? Students' and teacher's experiences of electronic portfolio (e-portfolio) systems in teacher education. In B. Hegarty, J. McDonald, \& S.-K. Loke (Eds.), Rhetoric and Reality: Critical perspectives on educational technology. Proceedings ascilite Dunedin 2014 (pp. 584-588).

Smith, J. and Spurling, A. (1999). Lifelong Learning Riding the Tiger, Cassell, London. 